must reinvigorate educational programs for both clinical care and clinical discovery research. In clinical education, practitioners of internal medicine should recommit to our traditions even as we embrace contemporary medical science and clinical practice improvements. As an academically based specialty, internal medicine has neglected the still-modern principles of diagnostic parsimony and therapeutic proficiency that have always distinguished the admired internist. It is not too late to emphasize again clinical care rooted in sound bedside skills and a scholarly approach to practice, further enriched by a deep appreciation for the influence of social and environmental factors on the risk for disease and the response to treatment. It is not too late, either, for our field to lead rather than follow the initiatives of this "global generation," which is dedicated to local and worldwide improvements in human health. These goals cannot be met if we continue to delegate the education of our students and trainees to our most junior, though talented, faculty. Senior faculty and physician-scientists who have fled the wards where students are inspired to choose careers in internal medicine and to adopt the values of our discipline must engage again if we are to realize the renewal of internal medicine and the long-term success of health reform.

Educational change is needed as well to inspire students and trainees to pursue clinical discovery research. Clinical discovery includes the translation of laboratory science to clinical care, as well as the clinical epidemiology and health services research that was "invented" by academic general internal medicine. Ironically, despite its leadership in developing these fields, which constitute the basic science of clinical practice, doctors practicing internal medicine have not succeeded in integrating these research achievements into either clinical education or clinical care. Health reform goals of decreased cost and improved outcomes depend on leadership from the field of internal medicine for advances in clinical discovery research that also advance human health. Without these commitments to innovation in education and research, health care reform will exchange improved access to care for worsening costs and quality.

In health care reform, government has responsibility for ensuring access to medical care for all Americans. Neither further policy analyses nor additional legislative actions will be sufficient to achieve either improved patient outcomes or diminished medical care costs. Achieving these goals is the responsibility of the profession of medicine. Internal medicine will need to lead in this effort by once again promoting effectiveness and efficiency as the hallmarks of medical care. In doing so, internal medicine will also have crafted a new and renewable social contract that holds the promise of delivering at last on our duty to always put the public interest ahead of our profession's self-interest.

\section{Ralph I. Horwitz}

Stanford University, Palo Alto, California, USA. E-mail: ralph.horwitz@stanford.edu.

J. Clin. Invest. 119:2859-2860 (2009). doi:10.1172/JCI41032.

\title{
Build it and hope that enough of them will come
}

$\mathrm{H}$ ealth care reform has been postponed for too long, and we all should be invested in seeing it succeed. Among other issues, there are workforce challenges that need to be solved. Where will we get the practitioners needed to provide accessible, highquality care to our aging population? How will we deal with the increasing amount of time it takes to become a fully trained physician? Will different approaches to care and reimbursement make medicine a less appealing profession in the future?

There are already too few primary care practitioners in many communities, and the shortage is projected to get worse. I don't think American medical schools can (or should) increase capacity to turn out enough primary care doctors to fix this problem. Even if classes were dramatically enlarged, there is no guarantee that the added medical students would choose primary care. A better approach would be to redefine the responsibilities of generalist and specialist physicians and allow other professionals - physician assistants, nurses, other extenders - to play bigger roles in delivering and coordinating care. If we are going to solve our future health care needs, medical education will need to do more to prepare students for working collaboratively as members of health care teams. Ideally, students preparing for careers in the various health professions should interact through joint educational experiences that foster mutual respect and understanding. We need to let go of the traditional hierarchy and the view that a physician must always be the person in charge. We should invest in training programs and career development for non-MD practitioners.

Clinical education has been impacted by revving up RVU (relative value units) expectations, regulating resident work hours, and shifting more patient care to ambulatory settings. It is difficult to cram in enough teachable moments and observations of disease progression. Concerns about litigation have led to increased oversight of residents and fellows by attending physicians. For all of these reasons, it takes young doctors longer to become fully trained and independent, which indirectly increases the cost of producing each new physician, both for individuals and for society. I think it's time to look at this problem in a new way.
One approach might be to reevaluate our one-size-fits-all curriculum. Each student is expected to master a defined body of material in college and in medical school, regardless of whether she or he intends to become a surgeon, a bench scientist, or a pediatrician. I'd like to see thoughtful exploration of alternative models, e.g., partitioning medical education into separate content tracks for surgeons, for generalists, for investigators, and so on. This would be analogous to PhD programs, which require students to differentiate early in their predoctoral education. Recognizing that most students aren't exposed to behind-the-scenes aspects of medical practice before entering medical school, a new curriculum might start with an introductory clinical experience that allows students to sample different physician careers before committing to a more specialized program. Tracks might begin early in medical school and extend through residency. Such an approach would not only decrease the period of training, but it might also create late-entry and reentry options for those who have delayed or interrupted their pro- 
fessional education because of other life experiences.

These are a few ideas, meant to instigate a more thorough, thoughtful examination. Major changes in training are hard for individual schools to implement unilaterally, because undergraduate medical education, residency, and fellowships are overseen by different accreditation organizations that have different perspectives and goals. But the time seems right for a national discussion, particularly following on a forwardlooking report that was recently released by a joint AAMC-HHMI expert committee (1). Describing competencies rather than courses needed by physicians of the future, this report could serve as a cornerstone for rethinking how we educate physicians.

As with health care reform in general, there will undoubtedly be trade-offs. A fresh look at medical education may expose what is bound to be one of many elephants in the crowded room of health care reform - students and their families pay large sums and assume heavy debt to obtain professional credentials to work in the service of society. The personal cost has been accepted in the United States until now, but there may be more pushback if either prestige or potential earnings are diminished. New models for financing the education of health care professionals may ultimately need to be on the table, too, as we think about better aligning incentives for a healthier population.

\section{Nancy C. Andrews}

Duke University School of Medicine, Durham, North Carolina, USA. E-mail: nancy. andrews@duke.edu.

J. Clin. Invest. 119:2860-2861 (2009). doi:10.1172/JCI41105.

1. AAMC-HHMI Scientific Foundations for Future Physicians Committee. 2009. Scientific foundations for future physicians. Association of American Medical Colleges/Howard Hughes Medical Institute. Washington, DC, USA. 46 pp.

\section{A view from a European medical academic who spends time in the US}

\begin{abstract}
A merican medicine has much to be proud of. Since World War II, the National Institutes of Health has sparked a revolution in academic biomedical research. There are world-leading academic hospitals delivering the best-quality health care, such as Johns Hopkins, the Mayo Clinic, Mass General, and the Hospital for Special Surgery, among others. Cancer care and outcomes are the world's best. But there are also problems on a huge scale, which means that the US's world-leading health expenditure ( $16 \%$ of GNP) is delivering health care that is worse than in much of Europe in terms of clearly analyzable indicators, such as infant mortality or length of life. European countries like the UK typically spend $8 \%-10 \%$ of GNP on health care. But that is not to say that European or British medical care doesn't have its own problems, as certain aspects - such as the UK's cancer survival rates - are worse than in the US.

The lower-percentage cost of health care in Europe covers all the population, while the US's $16 \%$ still leaves 45 million uncovered. Clearly there is an unanswerable case for major reform in order to deliver value for money, not just for the lucky ones able to avail themselves of the best hospitals, or of quality cancer care, but for all the population. The humanitarian principle - quality health care for all - that the European nations have espoused, though practised in different ways, leaves none of the population disadvantaged and uncovered.
\end{abstract}

The $16 \%$ of GNP spent on health care in the US is having dire economic consequences. That each of Detroit's US car manufacturers' vehicles allegedly has about $\$ 1,000$ of health care costs in its price is hard to comprehend, but its consequences are apparent. Costs of $16 \%$ and rising are clearly unsustainable. That most personal bankruptcies in the US are due to health care costs is also amazing. From a distance some of the causes of the cost differences of the US and European systems can be seen. Three are worth highlighting. The greater litigiousness of the US has led to "defensive medicine," with its unnecessary tests and treatment. This requires reform of the medico-legal interface to avoid blaming physicians for unfortunate but unpredictable events. Reducing claims and medical insurance costs would help reduce the total cost of health care. The culture of health insurers trying to make a profit from delivering health insurance is another problem that has been well documented; they cut costs by excluding coverage and care and having plans whose coverage is very difficult to understand. Wendell Potter, the Senior Fellow on Health Care for the Center for Media and Democracy, in his testimony to the US Senate Committee has clearly documented this problem (1). A controversial issue is the appropriateness of intensive care for late-stage terminally ill patients with no hope of recovery, with the Terri Schiavo case as a most dramatic example (2). Americans pay a huge cost for health care, and some estimate that half of lifetime medical costs occur in the last year of life; far more patients with terminal illness die after weeks in intensive care in US than Europe.

Having been in the US on holiday recently (August 2009), I saw some of the televised town hall debates. It is sad to see firsthand the misinformation and misunderstanding of many angry participants, frightened of change, frightened of losing benefits, frightened of "socialized" medicine like Britain's National Health Service (NHS), while not realizing what a poor deal they actually have from the current system, compared to their European and Canadian cousins.

The degree of misinformation is clearly illustrated by fears that chronic disease patients would be left to die. It was said by Investor's Business Daily in July 2009 that prominent scientist Professor Stephen Hawking (with Lou Gehrig's disease) would be left to die by socialized medicine in the UK's NHS (3). This sadly reflects the gross politicization of this debate. Hawking, as is well known, lives in the UK and has been kept alive for an amazingly long time by the care and devotion of the NHS. Enough said.

It is not appreciated by many that health care for the uninsured in the US is still paid for, by cross-subsidies. Instead of receiving lower-cost routine care from primary care physicians early in the disease process, these patients will eventually turn up when much more ill in the emergency rooms and 